\title{
El Pleistoceno Superior final en el sur de la Península lbérica
}

\author{
Sergio Ripoll lópez, F.J. Muñoz ibáñez y S. Pérez Marín*
}

$\begin{aligned} \text { RESUMEN } & \text { ABSTRACT } \\ \text { Este trabajo aborda el estudio del } & \text { This work approaches the study } \\ \text { Solutrense y del Magdaleniense } & \begin{array}{l}\text { of the Solutrean and Magdalenian } \\ \text { in Andalusia. They are analyzed }\end{array} \\ \text { las principales características } & \text { the principals chronologicals } \\ \text { cronológicas e industriales de cada } & \text { and industrials characteristics } \\ \text { período, con un especial énfasis } & \text { of each period, with a especial } \\ \text { en aquellos yacimientos clave } & \text { emphasis in those sites } \\ \text { que articulan la secuencia del } & \text { that articulate the sequence of the } \\ \text { Pleistoceno Superior Final. } & \text { Upper Pleistocene. } \\ \text { Asimismo, se incorporan } & \text { Also, they are incorporated } \\ \text { los descubrimientos realizados } & \text { the discoveries accomplished } \\ \text { en los últimos años y también } & \text { in the most recent years } \\ \text { se analizan aquellas estaciones } & \text { and they are also analyzed } \\ \text { cuya ubicación cronológica } & \text { those stations whose chronological } \\ \text { en estas etapas resulta } & \text { position in these stages results } \\ \text { conflictiva. } & \text { conflicting. }\end{aligned}$

\section{INTRODUCCIÓN}

En el momento presente los datos referidos al Pleistoceno Superior Inicial en la zona andaluza y levantina de la Península Ibérica están escasamente

* Universidad Nacional de Educación a Distancia, Facultad de Geografía e Historia, Departamento de Prehistoria e Historia Antigua. Avda. Senda del Rey, s/n 28040 Madrid. 
actualizados fundamentalmente por la ausencia de excavaciones recientes, dataciones, etc., con lo que se conocen a grandes rasgos los diferentes momentos ocupacionales, pero es difícil seguir la evolución interna de las distintas culturas.

A principios de siglo L. Siret sistematizó la Prehistoria del Sureste y si bien hizo mucho más hincapié en las épocas de los metales, también profundizo en sus estudios sobre el Paleolítico. La profusión de excavaciones realizadas en diversos yacimientos, fundamentalmente almerienses y murcianos, le permitieron establecer una secuencia cronocultural que ha estado vigente hasta hace pocos años.

Continuando de cierta forma los trabajos de Siret, a principios de este siglo, $\mathrm{H}$. Obermaier y $\mathrm{H}$. Breuil retomaron la investigación en la zona descubriendo cavidades con arte rupestre, además de realizar estudios más o menos sistemáticos en distintos yacimientos. Esta fecunda etapa se interrumpió durante bastantes años en los que únicamente el suizo J. Ch. Spanhi realizó algunos desafortunados sondeos en la Cueva de Carihuela de Granada, que todavía permanecen inéditos.

En los años sesenta, se iniciaron un conjunto de investigaciones sistemáticas en importantes yacimientos algunos de ellos desconocidos. Entre estas excavaciones destacan Cueva de Ambrosio, dirigida por el prof. E. Ripoll (1958-1962), la entonces recién descubierta Cueva de Nerja, en la que empezó a trabajar el prof. M. Pellicer junto con el prof. F. Jordá (19621990), Cueva Horá, dirigida también por el prof. Pellicer (1964) y posteriormente continuada por el prof. M. Botella, la Cueva de la Carihuela (Almagro Basch et alii, 1970), etc...

Esta etapa más o menos continuada se ha prolongado hasta la actualidad, donde cuestiones administrativas y económicas han vuelto a poner trabas a la investigación. Sin embargo durante algunos años se ha avanzado bastante en el conocimiento del Paleolítico Superior andaluz gracias a los proyectos centrados: en la Cueva de la Carihuela (Granada), dirigido por el Dr. G. Vega, la Cueva del Boquete de Zafarraya (Málaga), dirigido por C. Barroso y el Dr. J. J. Hublin, o La Cueva de Ambrosio, dirigido por el Dr. S. Ripoll López.

\section{EL SOLUTRENSE}

Esta extensa área geográfica, que engloba el sur peninsular, presenta una gran homogeneidad industrial en las diferentes fases del Solutrense y una dilatada tradición en la investigación del Paleolítico Superior, sobre 
todo en Andalucía Oriental. La región que tradicionalmente se ha denominado como sureste (Almería y Murcia) ha proporcionado desde antiguo importantes evidencias materiales de esta cultura, aunque desgraciadamente la mayoría de las estaciones cuentan con excavaciones muy antiguas. Así, como nexo de unión entre el sureste y Andalucía se sitúa la Cueva de Ambrosio que junto con la Cova del Parpalló son los dos yacimientos claves que definen la evolución de este tecnocomplejo. Por ello, la estación valenciana se convierte en un punto de referencia básico para estructurar la secuencia solutrense en Andalucía. En el resto de esta región; el Solutrense se ceñía a algunos yacimientos y hallazgos aislados en Málaga y Granada. Sin embargo, en los últimos años hemos asistido al descubrimiento de nuevas estaciones en las provincias de Cádiz, Córdoba y Jaén, que vienen a paliar el vacío existente entre el Solutrense andaluz y las áreas portuguesa y meseteña respectivamente. Por ello, se hacía necesario un trabajo de síntesis que pusiera al día y unificara los conocimientos sobre esta etapa cultural.

En total se han identificado 29 estaciones susceptibles de contener industrias solutrenses, aunque como se verá más adelante no es posible adscribir todas ellas con seguridad a este período. La distribución geográfica de los yacimientos a lo largo de la franja occidental y meridional de la península atestigua una amplia ocupación del territorio, sobre todo en las fases más avanzadas. En Andalucía Oriental domina el hábitat en cueva. Esta característica se mantiene en las etapas superopaleolíticas anteriores y posteriores al Solutrense. Mientras, en Andalucía Occidental la mayor parte de las industrias solutrenses aparecen en yacimientos al aire libre. La abundancia de este tipo de estaciones está sin duda condicionada por el hallazgo casi fortuito de las mismas. Su localización se debe a prospecciones sistemáticas de áreas concretas con escaso desarrollo de relieves calizos o a la identificación de materiales solutrenses mezclados con elementos de otras etapas culturales y fundamentalmente en superficie. El número de estaciones y hallazgos aislados podría hacer pensar en la existencia de un gran volumen de datos. Sin embargo, éste queda matizado por la cantidad y calidad de la información que aporta cada uno. Además, la mayor parte de los yacimientos no cuentan con publicaciones exhaustivas, quedándose en meros avances informativos.

Así, de los 29 yacimientos, sólo 14 presentan un contexto estratigráfico claro y definido. En 7 casos los materiales solutrenses aparecen revueltos con utillaje de otras etapas culturales o de otras fases solutrenses. En 8 estaciones nos encontramos con elementos aislados recogidos en superficie, bien sea al aire libre o en cueva o abrigo. Así mismo, son escasos los yacimientos que cuentan con estudios sedimentológicos, polínicos, 
faunisticos, radiométricos, etc., ya que o bien se trata de excavaciones antiguas o de industrias sin contextualización estratigráfica posible. No obstante, los útiles característicos que definen esta cultura y sus diferentes etapas hacen posible situar la mayor parte de los yacimientos en un contexto cultural relativamente satisfactorio.

En líneas generales el Solutrense de toda esta región, denominado Solutrense de facies Ibérica (Jordá Cerdá, F. 1955) aunque preferimos utilizar el término de Solutrense Extracantábrico en contraposición con el Solutrense de la cornisa cantábrica, donde se advierte una clara influencia francesa y de la zona clásica, es muy homogéneo. En todo este marco geográfico no aparecen facies locales que se aparten de los parámetros generales y cada etapa está definida por componentes industriales muy marcados. Sólo al final de este estadio se observa una cierta disgregación que ha llevado a algunos autores a una articulación algo más compleja de la secuencia (Fullola, J.Ma 1979 y 1994 y Villaverde, V. 1979 y 1992), aunque en gran medida esta diversificación es artificiosa.

La primera etapa, el Solutrense Inferior, no ha sido todavía identificada en Andalucía, aunque el aumento del número de estaciones y de los yacimientos en donde no se ha llegado a la base del relleno no permiten descartar la posibilidad de su existencia. Únicamente en la malagueña Cueva de Nerja, J.L. Sanchidrián (1994) cita la existencia de varias puntas de cara plana en el sondeo de la Sala del Vestíbulo (N.V. 10). Pero la presencia de este tipo de utillaje no certifica por sí misma la existencia de Solutrense Inferior, ya que también aparece en fases más avanzadas de este tecnocomplejo y el material procede de un pequeño sondeo con una muestra industrial muy reducida. Por lo tanto, solamente queda fehacientemente constatada la presencia de Solutrense Inferior en la comarca valenciana de La Safor, en la Cova del Parpalló (Pericot, L. 1942; Fullola, J.M ${ }^{a}$ 1979) y Les Mallaetes (Fortea, J. y Jordá, F.1976), a la espera que futuras excavaciones confirmen su presencia en Murcia y la comunidad andaluza.

Es durante el Solutrense Medio cuando este tecnocomplejo se extiende desde el teórico núcleo primario de La Safor a la provincia de Alicante y a Andalucia Oriental, llegando hasta la costa malagueña. Las estaciones que se adscriben a este período son la Cueva de Ambrosio (figura 1) (Ripoll Perelló, E. 1960-61 y 1962, Ripoll López, S. 1984 y 1988, Ripoll López, S. et alii 1997; Ripoll López, S. et alii 1997), la Cueva de Nerja (Jordá, F. 1986; Jordá cerdá et alii 1983 y 1991; Sanchidrián, J.L. et alii 1987) y El Bajondillo (Baldomero, A. et alii 1989-90; Baldomero, A. et alii 1991; Cortés, M. y Simón, M. 1997). 

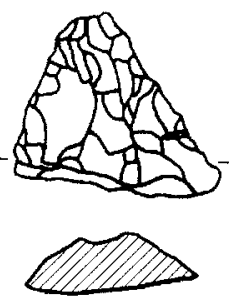

1
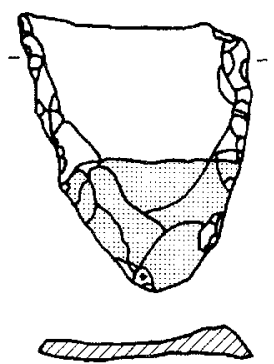

2
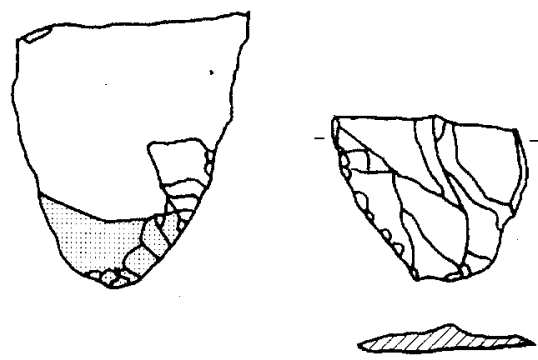

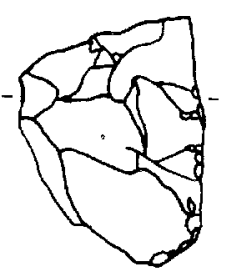

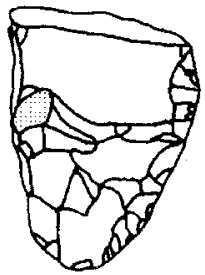

4
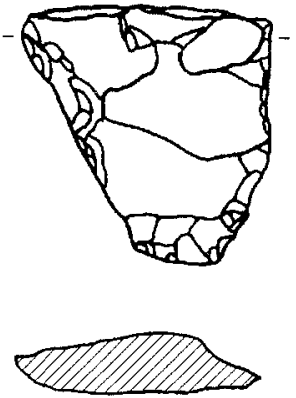

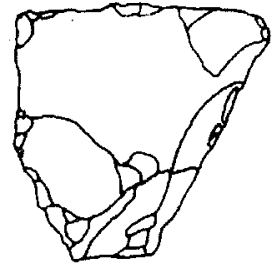

5
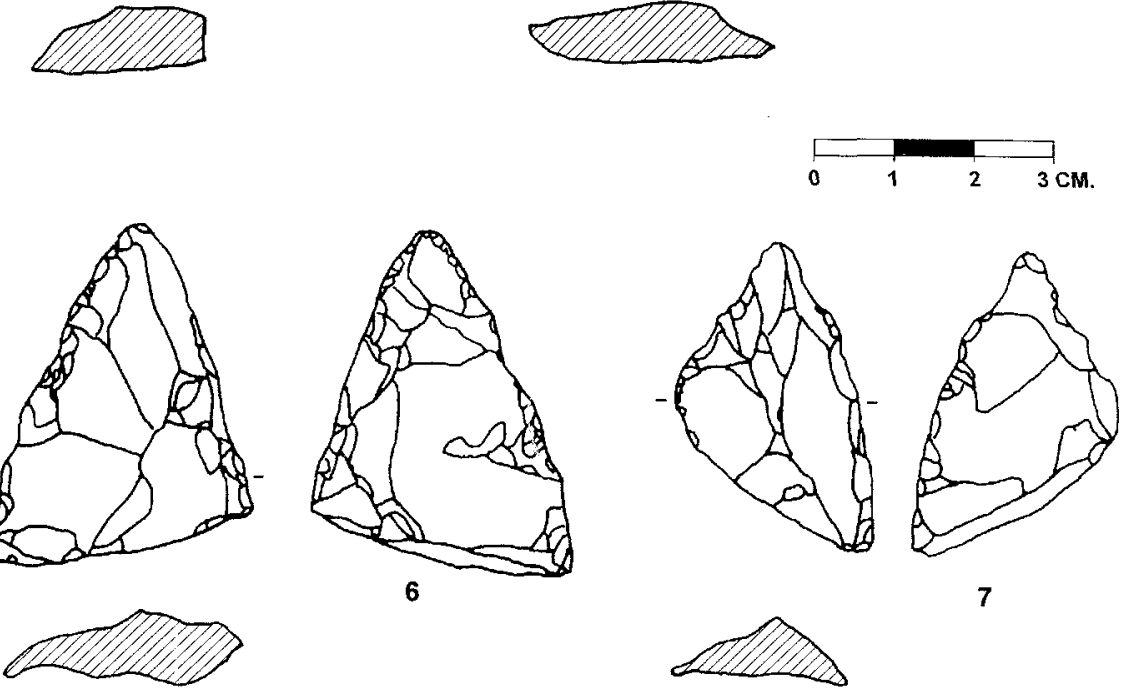

Figura 1. La Cueva de Ambrosio (Vélez Blanco, Almería). 1-5: punta de cara plana, 6-7: hoja de laurel. (N-VI: campañas 1983-86) Solutrense Medio. 
Para esta etapa contamos con cinco dataciones radiocarbónicas, incluyendo los datos del País Valenciano. En la cueva de Les Mallaetes el nivel Va del Sector Este ha sido fechado en $20.140 \pm 460$ B.P. (KN-l/919). En la Cueva de Ambrosio el nivel VI ha sido datado en $16.590 \pm 1400$ B.P. (GIF-7277). Por último, la Cueva de Nerja cuenta con tres fechas para el nivel 8 de la Sala del Vestíbulo que se sitúan en $18.420 \pm 530$ (UBAR-158), $17.940 \pm 200$ (UBAR98) y $15.990 \pm 60$ B.P (UBAR-157). La gran variación que presentan estas últimas para los tres subniveles del mismo estrato plantean la necesidad de no tenerlas en consideración al no presentar ninguna coherencia entre sí. Si se parte de la base de un foco originario para el Solutrense en la comarca de La Safor, que puede o no ser genético, lógicamente las fechas más antiguas para el Solutrense Medio deben situarse aquí. Así, la datación de Les Mallaetes parece indicar el 20.000-19.500 B.P. aproximadamente como punto de partida para el Solutrense Medio en éste núcleo primario. La nuevas ideas solutrenses llegarían a Andalucía algo más tarde, alrededor del 18.500 B.P., aunque la gran amplitud cronológica que ofrece la fecha de la Cueva de Ambrosio puede indicar una mayor antigüedad ya que el 16.590 B.P. sería una cronología excesivamente moderna para un Solutrense Medio.

El utillaje característico del Grupo Solutrense viene marcado por el predominio de las hojas de laurel sobre las puntas de cara plana que, no obstante, mantienen un peso relativamente importante. Por primera vez se detecta en el registro arqueológico las piezas solutrenses bifaciales cuya presencia es significativamente nula en el Solutrense Inferior. Estas piezas solutrenses bifaciales son esbozos de hojas de laurel cuyo proceso de fabricación no habría sido completado. Están realizadas sobre lascas que pueden alcanzar un tamaño considerable y sobre hojas, ambos soportes de gran espesor. Presentan un retoque plano generalmente por percusión, que en la mayoría de los casos no llega a ser invasor, donde la concavidad dejada por los levantamientos es muy acusada. No obstante, en algunas ocasiones también aparece un retoque más elaborado realizado por percusión indirecta con percutor blando. El Grupo Solutrense en la Cueva de Ambrosio llega hasta el 22,22\%, manteniendo porcentajes muy elevados en todos sus niveles. Este peso específico en el utillaje solutrense muy probablemente esté en relación con la funcionalidad del yacimiento, presumiblemente como lugar de renovación del utillaje lítico, y por la gran cantidad y calidad de las materias primas que se localizan en su área de captación. Desafortunadamente, no contamos con ningún análisis industrial pormenorizado.

Por primera vez aparecen útiles compuestos, fundamentalmente raspadores dobles, cuyos porcentajes muy bajos se mantendrán estables a lo 
largo de toda la secuencia. Algo similar ocurre en el Solutrense Medio para el utillaje elaborado sobre hojitas, aunque ausentes en la Cueva de Ambrosio sí se documentan en las estaciones valencianas y su importancia aumentará considerablemente en la siguiente fase. En el resto del utillaje se mantiene el predominio de los raspadores frente a los buriles. Así, en la Cueva de Ambrosio el I.R. alcanza el 40,74\%, mientras que el I.B. llega al $11 \%$. Hay un predominio acusado de los buriles diedros (I.B.d. $=8,33 \%$ ) frente a los realizados sobre truncatura (I.B.t. $=2,77 \%$ ).

Durante el Solutrense Superior se ha documentado una considerable ampliación del área geográfica a partir de las hasta ahora citadas. Además de la Cueva de Ambrosio en Almería (figura 2), aparece la Cueva del Tajo del Jorox en Málaga (Marqués, I. y Ruiz, C., 1976) y la Cueva del los Ojos en Granada (Toro, I., Almohalla, M. y Martín, E. 1984; Toro, I.y Almohalla, M. 1985). Hacia el interior y el occidente aparecen nuevas estaciones solutrenses en Jaén, con el yacimiento de Peña de la Grieta (Arteaga, O. et alii 1992; Arteaga, O. et alii 1993), y sobre todo en la fachada atlántica de la provincia de Cádiz. Aquí, se han localizado cuatro estaciones: Cueva del Higueral de Sierra Valleja (Giles, F. et alii 1992; Giles, F. et alii 199596), Llanos de don Pedro (Giles, F. et alii 1993; Gutiérrez, J. Mª et alii 1994, Giles, F. et alii. 1995-96), Cueva del Higueral (Giles, F. et alii 199596; Giles, F. et alii 1996) y La Fontanilla (Ramos, J. et alii 1992, Ramos, J. et alii 1995 y Ramos, J.R. et alii 1996). La mayoría de éstas no cuentan con excavaciones sistemáticas, pero los avances hasta ahora publicados auguran unas buenas perspectivas para el conocimiento del Solutrense en esta región.

Para el Solutrense Superior contamos con tan sólo tres dataciones de $\mathrm{C}_{14}$, con resultados bastante heterogéneos entre sí. En la Cova del Parpalló el tramo de 5-4,75 m. se ha fechado en $18.080 \pm 850 / 750$ B.P. (BM861 ), el nivel III del Sector Este de Les Mallaetes presenta una datación de $16.300 \pm 1500$ B.P. (KN-l/918) y, por último, la Cueva de Ambrosio cuenta con una fecha de $16.620 \pm 280$ BP. (GIF-7275). Estas dos últimas dataciones resultan anómalas en la secuencia Solutrense, ya que sus fechas son muy recientes. No parece probable que el Solutrense Superior alcance el 16.000 B.P. En el caso de Les Mallaetes la gran amplitud que presenta hace que haya que considerarla con muchas precauciones. Para la fecha de la Cueva de Ambrosio existe un problema de solapamiento con las dataciones existentes en el mismo yacimiento para los estratos inferior y superior. No obstante, el análisis polínico revela unas condiciones climáticas atemperadas, pudiéndolo situar en el interestadio de Lascaux. En espera de nuevos datos para los niveles del Solutrense Superior, parece lógico pensar que sus inicios se situarían hacia el 18.000 B.P. en la 

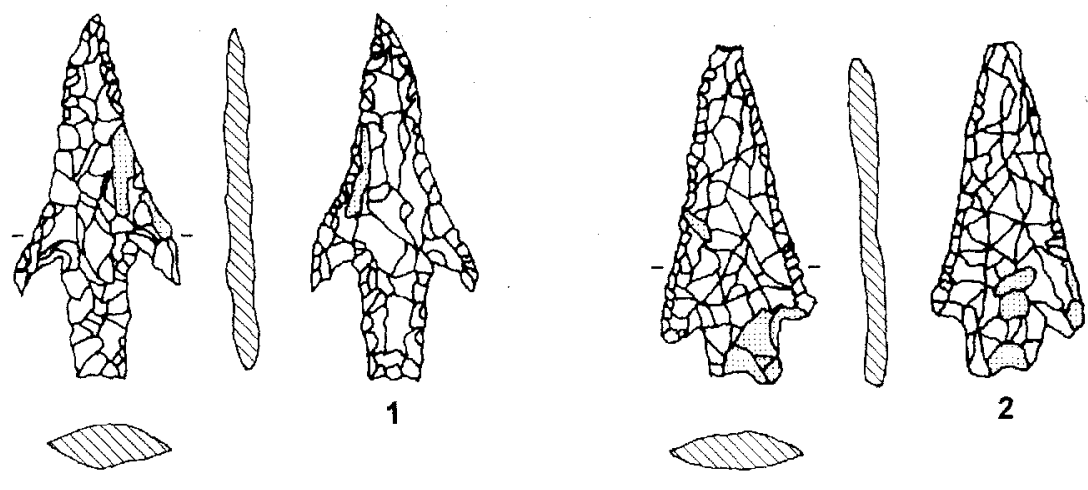

2
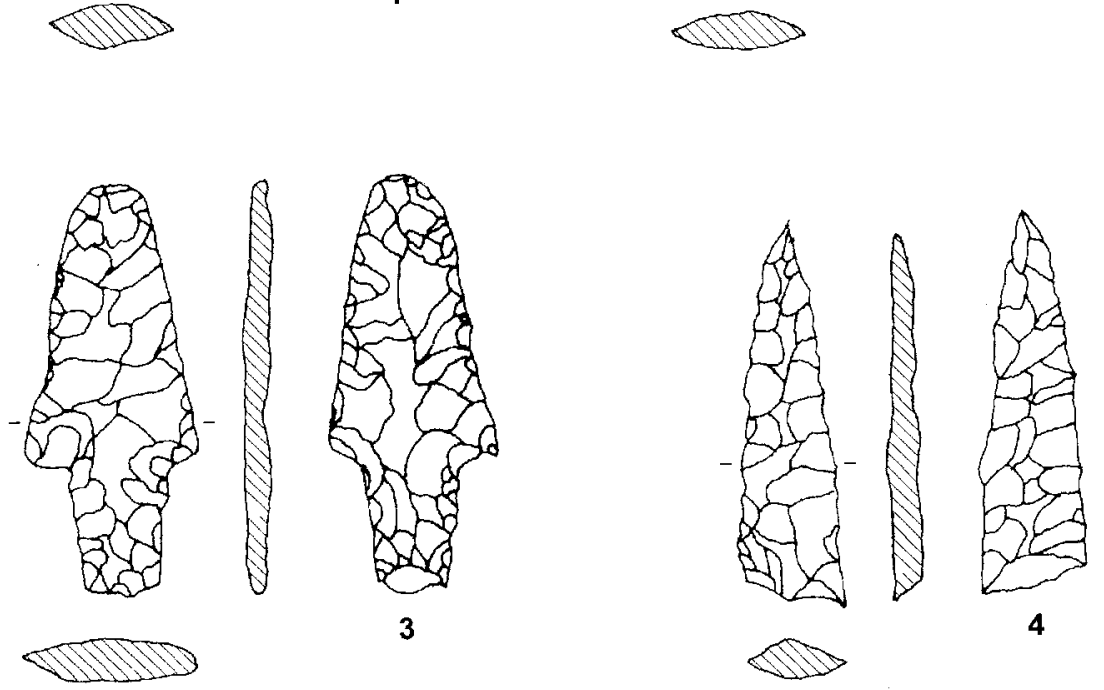

3

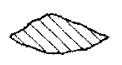

4
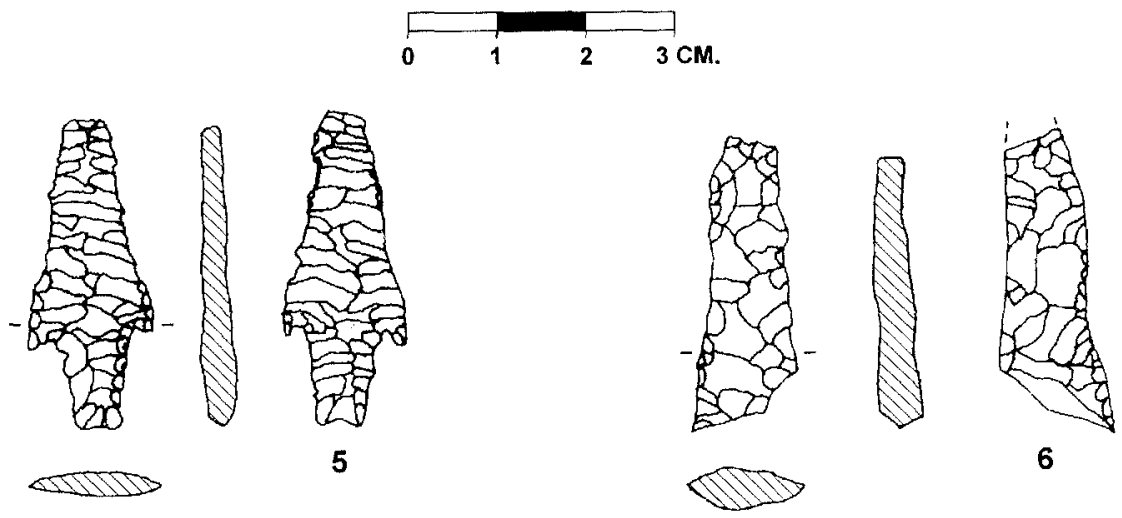

6

Figura 2. La Cueva de Ambrosio (Vélez Blanco, Almería).- Puntas de aletas y pedúnculo. 1-6: (N-Il: campaña 1990-92) Solutrense Superior Evolucionado. 
comarca de La Safor, donde la idea de la pedunculación de los proyectiles que desemboca en la aparición de las puntas de aletas y pedúnculo está presente en el final de la etapa anterior. Tanto hacia el norte como hacia el sur del núcleo valenciano, la incorporación de esta nueva adquisición tecnológica al acervo cultural parece que llegaría ya totalmente formada en fechas algo posteriores.

En el utillaje característico del Grupo Solutrense están todavía presentes las puntas de cara plana, aunque su porcentaje con respeto a la etapa anterior es mucho más restringido. Las hojas de laurel mantienen su importancia en el total de piezas de retoque plano. Dentro de este tipo de puntas aparecen ahora algunas hojas de bordes paralelos y rectilíneos que tradicionalmente se han considerado como hojas de sauce, por un desconocimiento de la tipología. Éstas, que sólo aparecen en Francia y el norte de la Península Ibérica, presentan un retoque unifacial en el anverso; aunque en algunas ocasiones pueden tener levantamientos aislados en la cara bulbar. Sin embargo, en el Solutrense Extracantábrico todas presentan un retoque bifacial que cubre por completo ambas caras. Los primeros ejemplos de este tipo de proyectiles aparecen en Les Mallaetes al final del Solutrense Medio. Por lo tanto, se puede asegurar que en el Solutrense andaluz no existen verdaderas hojas de sauce, aunque este tipo de puntas podrían ser el equivalente de las que aparecen en el Mediterráneo; características ambas del Solutrense Superior.

Las puntas de aletas y pedúnculo, se convierten en los útiles distintivos de este período, firmemente asentados en todas las zonas, después de los primeros esbozos realizados al final de la etapa anterior. Alcanzan valores. bastante importantes en algunos yacimientos como la Cueva de Ambrosio, la Cueva del Higueral (figura 3) o la Fontanilla.

El último tipo de proyectil representativo de este período es la punta de muesca de tipo mediterráneo. Su reaparición en este momento, junto con el aumento del utillaje sobre hojita, testimonia una vuelta de las influencias gravetienses que se mantendrán cada vez con más fuerza en el Solutrense hasta la desaparición del mismo. Este tipo de proyectiles son eliminados de los conjuntos industriales durante casi 3000 años. Su importancia será cada vez mayor. En conjunto, las puntas de muesca se convierten en los proyectiles más importantes en la región valenciana, mientras que en el resto de los yacimientos son las puntas de aletas y pedúnculo el elemento más característico. Las piezas solutrenses bifaciales mantienen su presencia en el registro arqueológico en una intensidad similar a la de la etapa anterior.

Los valores que alcanza el Grupo Solutrense en este período son, en general, superiores a la etapa anterior; llegando al $22 \%$ en la Cueva de 

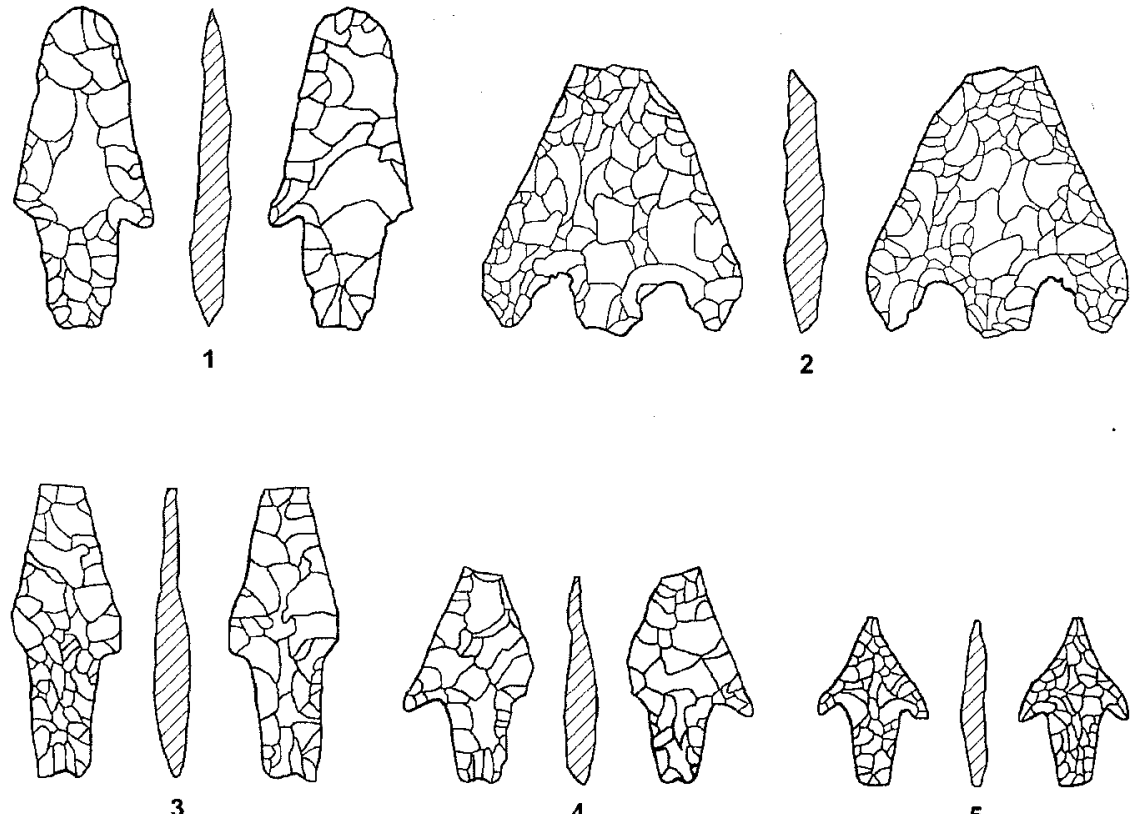

3
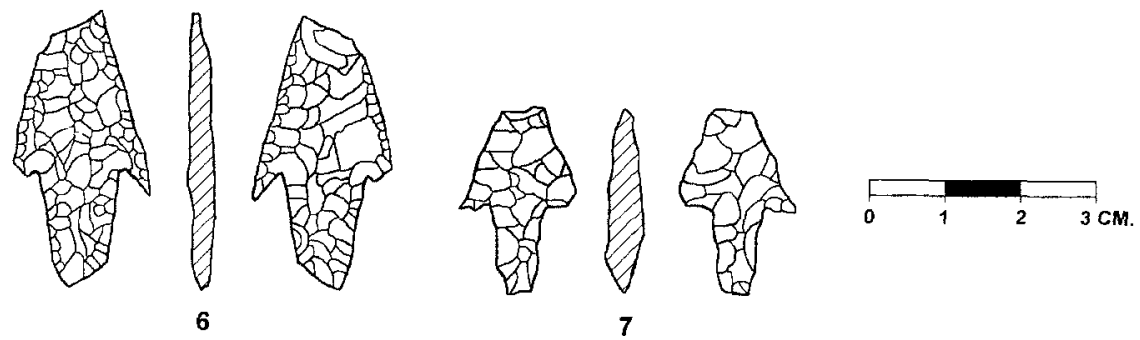

Figura 3. Cueva del Higueral (Jerez de la Frontera, Cádiz). 1-7: punta de aletas y pedúnculo. (4) Solutrense Superior.

Ambrosio (figura 4). Aunque en el resto de yacimientos con estratigrafías fiables no superan el $4 \%$. En este índice se han incluido también las puntas de muesca de tipo mediterráneo ya que han sido consideradas como un elemento tan característico del utillaje del Solutrense de tipo Ibérico como lo pueden ser los proyectiles de retoque plano.

En cuanto al resto de la composición industrial, el I.R. sigue dominando al I.B., aunque en algunas estaciones esta preponderancia no es ya tan acusada. Este sería el caso de la Cueva de los Ojos, donde los porcentajes 

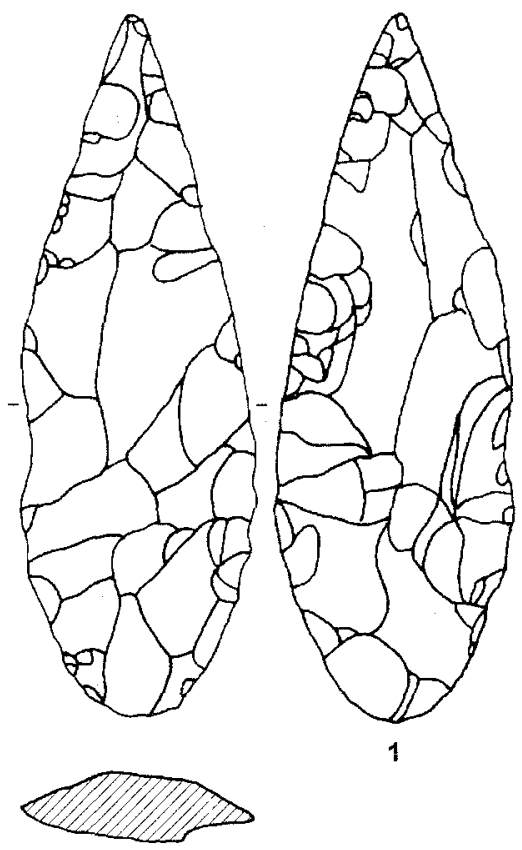
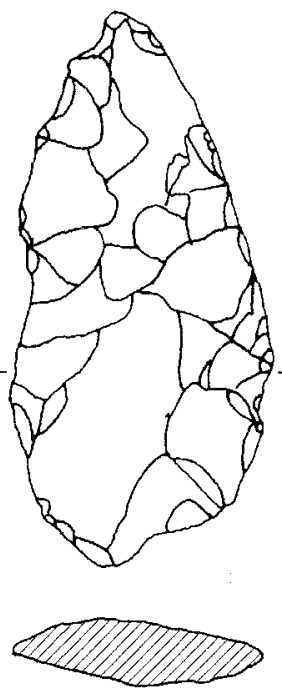

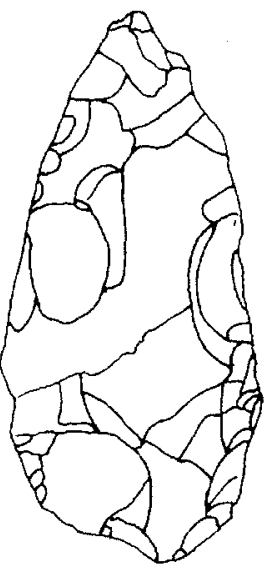

2
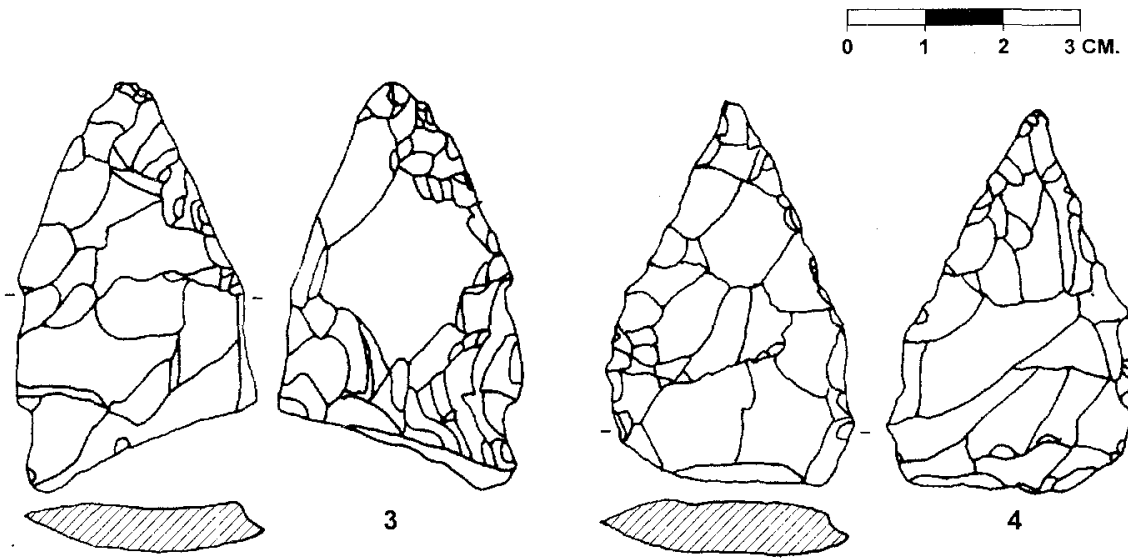

3
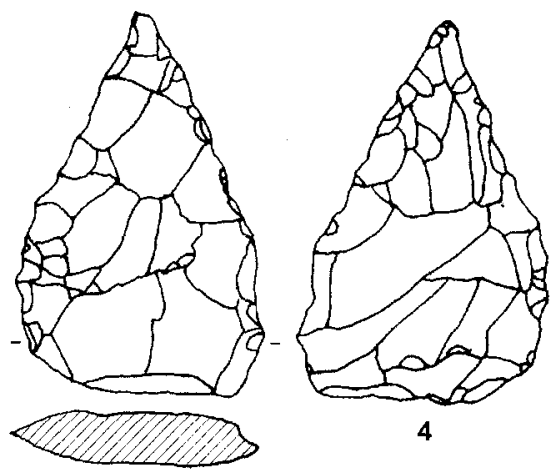

Figura 4. La Cueva de Ambrosio (Vélez Blanco, Almeria).- 1-4: hoja de laurel. (N-IV: campaña 1962) Solutrense Superior. 
están casi igualados. Los útiles compuestos se mantienen en valores similares a la fase anterior. Junto con la aparición y difusión de nuevos morfotipos de proyectiles, lo más significativo de este período es el aumento de utillaje sobre hojita, fundamentalmente hojitas de dorso. En todos los yacimientos con estratigrafías fiables para el Solutrense Superior el I.h. se sitúa en valores próximos al 7,04\% de la Cueva de Ambrosio.

Durante el siguiente período los yacimientos solutrenses ocupan las mismas zonas geográficas que en la etapa anterior. Se han localizado un total de cuatro estaciones asociadas al Solutrense Superior Evolucionado. Estas son la Cueva de Ambrosio en Almería, Pantano de Cubillas en Granada (Toro, I. y Almohalla, M. 1979; Toro, I., Almohalla, M. y Argamasilla, M. 1980; Toro, I., Almohalla, M. y Martín, E. 1984), El Bajondillo (Málaga) y la Cueva del Higueral de Sierra Valleja (Cádiz). En este último, el nivel $3 A$, es adscrito por sus excavadores a esta etapa, sin embargo, no cuenta con una publicación detallada de sus materiales y sólo se cita la presencia de algunas puntas de aletas y pedúnculo. Aunque numéricamente sea inferior a las del Solutrense Superior, esta diferencia queda matizada por la abundancia de yacimientos que se encuadran entre esta etapa y el Solutrense Superior.

EI Solutrense Superior Evolucionado presenta cuatro dataciones radiocarbónicas. En la Cova del Parpalló el tramo 4,25-4 m. está fechado en $17.900 \pm 340$ (BIRM-521). En la provincia de Alicante hay dos dataciones, una para la Ratlla del Bubo (Soler, B. et alii 1990) y otra para Cova Beneitc (Iturbe, G. y Cortell, E. 1987), cuyas fechas oscilan entre el $17.360 \pm$ 180 B.P. (LY-5809) del nivel II y el $16.500 \pm 480$ B.P. (LY-3593) del nivel B2 respectivamente. Por último en Almería el nivel II de la Cueva de Ambrosio presenta una datación de $16.500 \pm 280$ B.P. (GIF-7276). La fecha de la Cova del Parpalló parece excesivamente antigua para establecer el inicio de esta etapa, posiblemente esté algo envejecida por la naturaleza misma de la muestra (colágeno). Como ocurre en las etapas precedentes el Solutrense Superior Evolucionado comenzaría algo antes en la región valenciana, donde el peso específico de las puntas de muesca es evidente en la etapa anterior, que en el sur y oeste peninsular; probablemente hacia el 17000 B.P., siendo sustituido por el Magdaleniense Inferior documentado en la propia Cova del Parpalló (Aura, J.E. 1989 y 1995b). En Murcia y Andalucía esta última fase solutrense sería sustituida por el Magdaleniense Medio como se constata en la Cueva del Caballo (Martínez Andreu, M. 1994) y en la Cueva de Nerja (Jordá, J. 1986) como yacimientos más importantes. Tanto el nivel III de Les Mallaetes como el nivel B2 de Cova Beneito y el nivel II de la Cueva de Ambrosio indican el inicio de una evidente mejoría climática. 
En cuanto al utillaje característico del Grupo Solutrense las puntas de cara plana casi desaparecen por completo. Sólo están presentes en el nivel II de la Cueva de Ambrosio donde se registran dos ejemplares. Las hojas de laurel continúan estando presentes en casi todos los yacimientos, aunque su número disminuye considerablemente con respecto a la etapa anterior. Las puntas de aletas y pedúnculo, cuyo descenso es muy significativo en el País Valenciano, en Murcia y Andalucía su presencia es todavía importante. Sin duda alguna, el útil más característico de toda esta etapa es la punta de muesca de tipo mediterráneo. Su presencia se constata en todos los yacimientos del Solutrense Superior Evolucionado y supera en número a cualquier otro proyectil del Grupo Solutrense. Su hegemonía es especialmente abrumadora en algunos yacimientos como en el Pantano de Cubillas (figura 5). Por último, las piezas solutrenses bifaciales mantienen su presencia en bastantes yacimientos, con valores variables según los mismos.

El Grupo Solutrense, donde también se han incluido las puntas de muesca de tipo mediterráneo, presenta índices bastante elevados con respecto a la etapa anterior en todos los yacimientos. En líneas generales, superan con creces el $10 \%$ del total. En las estaciones con una posición estratigráfica correcta destaca el nivel II de la Cueva de Ambrosio (G.S.= $21,75 \%$ ) o el nivel X de Pantano de Cubillas (G.S. $=14,66 \%$ ). Sin embargo, si se toman únicamente los útiles de retoque plano, queda constatado un gran descenso del G.S., que constituye una característica esencial del Solutrense Superior Evolucionado. Esta tendencia es más acusada en los yacimientos valencianos, donde el cambio cultural al Magdaleniense es más antiguo que en el ámbito andaluz. Aquí el retoque plano todavía es relativamente importante.

En cuanto a la relación raspador-buril, en todos los casos es siempre favorable al primero; excepto en el yacimiento de Pantano Cubillas donde el I.R. $(10,66 \%)$ es ligeramente inferior al I.B. (14,66\%). En esta etapa, la tendencia acusada de un predominio de los buriles diedros con respecto a los buriles sobre truncatura, documentada ya en algunos yacimientos del Solutrense Superior, es generalizada.

Por último, el utillaje sobre hojita presenta un avance muy significativo con respecto a la etapa anterior. Ahora, en todas las estaciones el I.h. es superior al $10 \%$. Destaca sobre todas ella el $28,7 \%$ de la Cueva de Ambrosio, a pesar de la importancia que mantienen el retoque plano. En el caso opuesto se encuentra el tramo superior de la Cova del Parpalló (I.h.= $7,06 \%$ ) que dará paso a un Magdaleniense Inicial de tipo Badagouliense. Así, en los yacimientos donde el repertorio solutrense es muy escaso y 


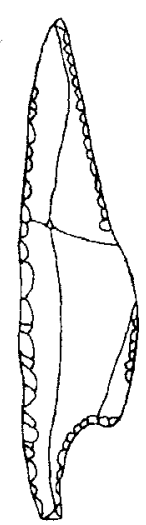

1

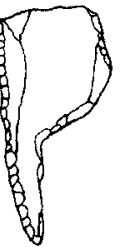

8

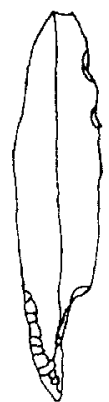

2

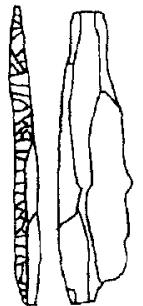

3

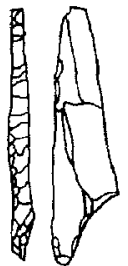

4

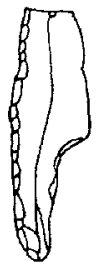

5

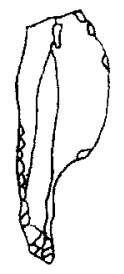

6

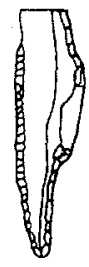

7.
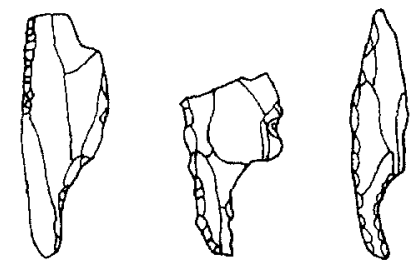

11

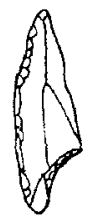

12
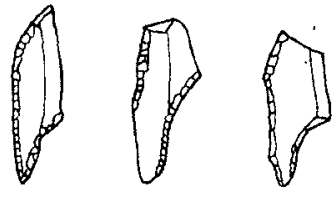

13

14

15

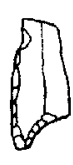

16

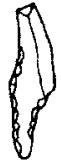

17

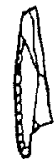

18

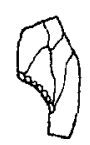

19
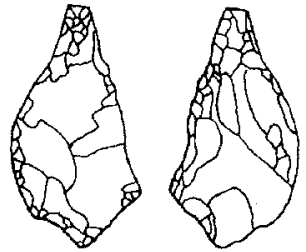

20

Figura 5. Pantano de Cubillas (Albolote, Granada).- 1-19: punta de muesca, 20: punta de aletas y pedünculo en proceso de fabricación. $(X)$ Solutrense Superior Evolucionado.

donde se repiten los mismos tipos de proyectiles para el Solutrense Superior y para el Solutrense Superior Evolucionado, el porcentaje que alcanzan los útiles sobre hojita se convierte en un elemento a tener muy en cuenta para insertarlos en una u otra fase. Como ya se ha visto, el I.h. en el Solutrense Superior se sitúa en valores muy próximos al 10\%, pero sin 
sobrepasarlo, mientras que en el Solutrense Superior Evolucionado este índice se sitúa en cifras superiores, a partir del $12-13 \%$.

El resto de los yacimientos no han podido ser incluidos en ninguna de la etapas concretas que articulan la secuencia solutrense. Generalmente, se trata de estaciones sin contexto estratigráfico, donde los materiales aparecen en sedimentos revueltos, de hallazgos aislados o recogidas superficiales. También aparecen reflejados aquellos depósitos que todavía no cuentan con una publicación exhaustiva que permita una adscripción cronoestratigráfica precisa.

En primer lugar, se analizan brevemente los yacimientos que, aún perteneciendo al Solutrense, no es posible incluirlos en ninguna fase concreta. El yacimiento almeriense de Chiquita de los Treinta (Pericot, L. 1949, Jordá, F. 1955; Fullola, J.M ${ }^{-} 1979$ y 1994) cuenta con la sola presencia de una hoja de laurel hallada en superficie. En la provincia de Granada, J.L. Sanchidrián (1994) cita la existencia de depósitos solutrenses inéditos en la Cueva de Malalmuerzo. Algo similar ocurre en la estación malagueña de la Cueva de la Araña (Ramos, J. en prensa), a la espera de la publicación de las actas del "I Symposium de Prehistoria de la Cueva de Nerja». En la provincia de Cádiz, el yacimiento de La Escalera 3 (Giles, F. et alii 1993; Giles, F. et alii 1995-96) presenta una secuencia estratigráfica coherente. En su nivel 2 se recuperaron un total de 11 útiles, entre los que destaca una hoja de laurel y una pieza solutrense bifacial. Debido a la escasa riqueza material del sondeo sólo se puede señalar la existencia de un Solutrense sin más precisión. El último yacimiento andaluz se trata del Río Palmones en Cádiz (Ramos, J. et alii 1995). Aquí, en un contexto MagdaIeniense y Epipaleolítico ha aparecido una hoja de laurel, sin que se pueda establecer ninguna consideración estratigráfica.

Un segundo bloque se agrupan las estaciones que podrían pertenecer al Solutrense Superior o al Solutrense Superior Evolucionado, pero que es imposible o muy difícil discernir a qué período se adscriben. En todas las estaciones, ante el escaso volumen de material y la procedencia del mismo es imposible establecer una cronología más precisa. En el yacimiento almeriense de la Cueva del Serrón-La Palica (Fortea, J. 1970; Cacho, C. 1980), en las escombreras de las excavaciones de L. Siret, aparecieron tres hojas de laurel, una punta de aletas y pedúnculo y una punta de muesca entre un total de 52 útiles. En la estación cordobesa del Pirulejo (Asquerino, Man. 1992 y 1993), en el nivel 4 al que le sigue un estrato magdaleniense, se ha identificado una punta de aletas y pedúnculo. En el Boquete de Zafarraya, en Málaga (Barroso, C. et alii 1991), en los sedimentos revueltos pertenecientes a depósitos Pleistocenos y Holocenos, 
se encontraron una hoja de laurel, una punta de aletas y pedúnculo y una punta de muesca. Asimismo, en la Cueva del Higuerón-Suizo y, también sin posición estratigráfica, se documentan dos puntas de aletas y pedúnculo, una de las cuales podría ser postpaleolítica (López, P. y Cacho, C. 1979), y una punta de muesca. En el Complejo del Humo (Sanchidrián, J.L. 1994) se localizó en superficie una punta de aletas y pedúnculo asociada a unas hojitas de dorso. Ya en la provincia de Cádiz, en Benalup de Sidonia, aparecen algunos yacimientos conflictivos. El abrigo de las Cuevas de Levante (Sanchidrián, J.L. 1992; Ripoll López, S. Mas, M. y Perdigones, L. 1993) cuenta con una prospección que dio como resultado una hoja de laurel y una punta de muesca. Posteriormente, se realizó una excavación del relleno y en el nivel lla se localizó una punta de aletas y pedúnculo, una punta de muesca y una pieza solutrense bifacial. El I.h se sitúa en el 9,26\%. Estos datos apuntan a una fase de transición entre el Solutrense Superior y el Solutrense Superior Evolucionado. Sin embargo, al tratarse de un depósito en posición secundaria y sistemáticamente lavado, puede que el sesgo de la muestra sea importante. En el abrigo de la Cubeta de la Paja, los materiales que publicó J.L. Sanchidrián (1992), son en realidad de una mezcla de recogidas superficiales en varios puntos de la zona próxima a este yacimiento, entre los que se incluyen las estaciones del Tajo de las Figuras y El Chorrito (Mas Cornellá, M. comunicación personal). Aunque no se puede saber con seguridad si los proyectiles que se incluyen en la Cubeta de la Paja (una punta de aletas y pedúnculo, una punta de muesca y una pieza solutrense bifacial) pertenecen realmente a este yacimiento o se trata de recogidas en diversos puntos aislados. Por último, la revisión de las colecciones antiguas del yacimiento gibraltareño de Sewell o Cueva «S» (Giles, F. et alii 1996) dio como resultado la identificación de una punta de aletas y pedúnculo y una punta de muesca.

Hay un último grupo de yacimientos cuya inclusión en el mundo Solutrense resulta muy problemática. Se trata de estaciones que únicamente cuentan como posible elemento característico del Solutrense las puntas de muesca de retoque abrupto. La presencia por si misma de este tipo de proyectiles no certifica la adscripción de estos materiales al Solutrense Final. Las puntas de muesca de retoque abrupto aparecen en el mediterráneo occidental desde el Gravetiense. Así queda atestiguado en diferentes yacimientos del levante peninsular como en la Cova del Parpalló (Fullola, J.M ${ }^{\mathrm{a}}$ 1979) o en Les Mallaetes (Fortea, J. y Jordá, F. 1976), por citar los dos ejemplos más característicos. Sin embargo, también este morfotipo se halla en contextos magdalenienses, como muestran los ejemplares encontrados en el Tossal de la Roca (Cacho, C. et alli 1995). Incluso 
las puntas de muesca se han encontrado en depósitos holocenos (Martí, B. y Gil, J. 1978; Plá, E. 1978). Por lo tanto sólo la asociación de este tipo de proyectiles con elementos de retoque plano asegura el carácter Solutrense de aquellos (Muñoz, F.J. 1997).

Se podría pensar que este tipo de conjuntos industriales responderían a la última fase del Solutrense propuesta por J.Mª Fullola (1978), el Solútreogravetiense II, donde las puntas de retoque plano desaparecen. No obstante, este hecho sólo ha podido ser constatado en el tramo final de la secuencia solutrense de la Cova del Parpalló (4-3,75 m), donde sin embargo, han aparecido una hoja de laurel y una pieza solutrense bifacial. En el resto de los yacimientos del Solutrense Superior Evolucionado solamente existen dos casos donde únicamente hay puntas de muesca como elemento caracterizador del Solutrense. En la Ratlla del Bubo, en Alicante, la datación radiométrica de $17360 \pm 180$ B.P., corrobora la inclusión del nivel II en esta etapa. Sin embargo, la escasa extensión del área excavada no descarta la aparición de utillaje bifacial de retoque plano. La otra estación es el yacimiento malagueño del Bajondillo. La polémica que ha girado en torno a la excavación de urgencia de sus depósitos y las vicisitudes que han podido sufrir sus materiales, no la convierten en elemento de referencia más idóneo para la existencia de un Solutrense Superior Evolucionado sin utillaje de retoque plano.

En Almería, la Cueva de los Morceguillos, con tres puntas de muesca, ha sido adscrito al Perigordiense $\mathrm{V}$ de la facies Font-Robert (Cacho, $\mathrm{C}$. 1980). La existencia de dos buriles Bassaler, característicos del Perigordiense Superior, han sido algunos de los elementos principales en que esta autora se apoya para su clasificación. No obstante, como se ha demostrado en páginas anteriores, durante el Solutrense Final se producen importantes variaciones en la proporción raspador-buril y aparecen cada vez en mayor proporción elementos característicos del Gravetiense. Otros investigadores, como J. Fortea (1986), plantea que estas dos estaciones pertenecerían sin ningún tipo de dudas al Solutrense Superior Evolucionado. Sin embargo, la antigüedad de las excavaciones, realizadas por $L$. Siret, y el número de piezas retocadas (51) no permiten realizar muchas precisiones cronoculturales. Por ello, es prácticamente imposible diferenciar a que etapa del Paleolítico Superior pertenecen. Algo similar ocurre en los yacimientos gaditanos de Casa de Postas (Ramos, J. R. et alii 1995), un hallazgo aislado al aire libre de una punta de muesca, y Abrigo del Bombín (Giles, F. et alii 1995-96), con una punta de muesca en superficie asociada a un posible enterramiento, lo que reduce considerablemente las posibilidades de su clasificación como Solutrense). En todos estos casos la escasez del utillaje y su poca representatividad dentro del 
Paleolítico Superior hace imposible saber si se trata o no de proyectiles solutrenses. Así, los yacimientos que únicamente contienen puntas de muesca de retoque abrupto no pueden, estrictamente, ser considerados como solutrenses; aunque algunos de ellos probablemente hayan contenido industrias pertenecientes a este período. Sin embargo, en el estado actual de nuestros conocimientos es imposible diferenciar cuales son éstos.

\section{EL MAGDALENIENSE}

Hasta la fecha existen muy pocos datos que nos hablen de la existencia de Magdaleniense en Andalucía. Además, debido a la perduración de las industrias Solutrenses en la región, el Magdaleniense parece estar representado en sus momentos finales.

De todos es conocido la existencia de Magdaleniense Superior en los yacimientos de la Hoyo de la Mina, la Cuevas del Higuerón y la Victoria en Málaga. En todos ellos y ante la ambigüedad de las industrias líticas, es la presencia de industria ósea lo que permite incluir estos yacimientos dentro de un Magdaleniense Superior Pleno (Fortea, J. 1984).

De la Cueva del Higuerón se conocía un arpón con una hilera de dientes (Giménez, S. y Laza, M. 1962; López, P. y Cacho, C. 1979), al que se suman otros dos procedentes de la vecina Cueva de la Victoria (Ripoll Perelló, E. 1970). La identificación de otra pieza de similares características, es lo que permite clasificar la industria de Hoyo de la Mina, dentro de las fases finales del Magdaleniense (Such, M. 1919; Fortea, J. 1973).

Desde los años ochenta, son conocidos los trabajos de excavación en la Cueva de Nerja (Málaga), en la Sala de la Mina se han documentado varios niveles clasificados como Magdaleniense Superior (NM XIV, XV y XVI) y otros como Epipaleolítico (NM XIII y XII). La industria se caracteriza por una fuerte presencia de hojitas de dorso, una relación raspador-buril favorable a este último y una importante presencia de industria ósea (Jordá Cerdá, F 1986). La capa NM XVI ha proporcionado dos fechas radiocarbónicas $12.270 \pm 220$ B.P. (UGRA-98) y $12.060 \pm 150$ B.P. (UGRA147) sincrónicas a otros contextos encuadrables dentro del Magdaleniense Superior como, Tossal de la Roca (Corte Interior nivel-I y nivel II) y Matutano (niveles lb, llb y III) (Cacho, C. 1995; Olaria, C. 1997).

Con respecto a la industria ósea se han identificado punzones, micropunzones, agujas, varios arpones, un posible bastón perforado realizados en hueso y algunas azagayas y puntas con motivos geométricos en asta. 
También destaca la aparición de arte mueble a partir de varios cantos decorados con motivos geométricos.

Los datos faunísticos señalan la existencia de conejo, cabra, ciervo, junto con otros recursos marinos que evidencian la existencia de pesca y marisqueo (Jordá Pardo, J.F. 1986).

El transito Pleistoceno Superior Final-Holoceno se identifica en el nivel NM XV, que se caracteriza como un clima templado y húmedo, con algunas pulsaciones frías que da como resultado la aparición de un lecho de gelifractos. La mejoría climática irá acompañada de un régimen de lluvias de carácter de arrollada. El contacto entre los niveles Magdaleniense Superior y Epipaleolítico de la Cueva de Nerja (Sala de la Mina NM XIII y XII) es erosivo. Estos han sido adscritos según las facies de J. Fortea a un Epipaleolítico Microlaminar Mediterráneo, que se identifica por un marcado carácter regional y un origen Magdaleniense, cuya industria refleja «un fenómeno de estancamiento cultural» con un claro predominio de los buriles sobre los raspadores (González Tablas, F.J. 1986).

El yacimiento de El Pirulejo, en la provincia de Córdoba es hasta la fecha el único yacimiento con niveles Magdalenienses en Andalucía occidental; fue descubierto en los años ochenta de manera casual y ha sido excavado desde entonces por $M^{a} \mathrm{D}$. Asquerino durante varias campañas (1992a, 1992b, 1993).

Bajo varios enterramientos correspondientes a la Edad del Bronce, se han documentado dos niveles clasificados como Magdaleniense Final (n 23) y un único nivel correspondiente al Solutrense (n-4).

Los resultados publicados hasta la fecha, muestran la existencia de una abundante industria lítica caracterizada por un dominio de los útiles sobre hojita y una relación raspador-buril variable según los niveles -favorables los primeros en los niveles superiores-. La diferencia fundamental con los niveles solutrenses es la ausencia de industria ósea y la existencia de una punta de pedúnculo y aletas.

Durante el proceso de excavación se han documentado varias estructuras: agujeros de poste, mamparos de piedra y algunos hogares ligeramente en cubeta, de pequeñas dimensiones y delimitados por piedras. Así como diversos restos de fauna entre los que se identifican, conejo, ciervo, cabra y suido (Asquerino, M르. 1992a).

Se han recuperado además, algunos objetos de adorno constituidos en su totalidad por colgantes realizados a partir de conchas, moluscos marinos y terrestres. También, se han encontrado más de ochenta plaquetas, bloques y cantos de caliza y arenisca, que en muchos de los casos 
presentan restos de ocre y en otros múltiples, trazos incisos. Hasta la fecha no se ha identificado ninguna representación pintada, pero sí una figura animalística grabada. Se trata de una plaqueta de arenisca en la que se observa un protomos de caprino orientado hacia la izquierda (Asquerino, $M^{a}$ D. 1992a).

Recientemente ha sido publicado (Ramos, J.R. et alii, 1995) la existencia de un posible asentamiento al aire libre en una terraza del río Palmones en la Bahía de Algeciras (Cádiz). Se han inventariado más de 3.000 piezas líticas y algunos restos de fauna. El estudio de la industria ha revelado la presencia de raspadores, buriles - con un ligero predominio de los primeros- numerosas muescas, denticulados y hojitas, algunas de ellas claramente identificables como hojitas tipo Montbani, así como la presencia de trapecios, microburiles y una pieza foliácea que pueden llevar a un error en su clasificación. La existencia de fauna está atestiguada mediante algunos restos de caballo, ciervo y lobo. Este asentamiento ha sido interpretado como un posible área de taller, aunque no se descarta la zona como lugar de hábitat, a pesar de la ausencia de posibles estructuras. Este conjunto ha sido clasificado como Magdaleniense Superior (RAMOS, J.R. et alii, 1995), sin embargo por las características de su industria podría encuadrarse más fácilmente dentro del Epipaleolítico, no sin ciertas dudas, debido a la existencia de algunas piezas que apuntan a etapas más recientes (Cacho, C. 1997).

El último momento del Paleolítico Superior en Andalucía, el Magdaleniense, nos proporciona una información muy desigual, y hasta la fecha no muy rica. Hasta los años ochenta únicamente el Magdaleniense era reconocido en algunos yacimientos -Hoyo de la Mina, El Higuerón, Cueva Victoria-, a partir de la industria ósea, característica pero poco abundante, compuesta casi exclusivamente por arpones, puesto que la industria lítica era poco típica.

Por el momento continúan siendo pocos los datos que atestigüen la existencia de las últimas etapas de Pleistoceno Superior Final o Magdaleniense en la región. Aunque este panorama parece estar cambiando a partir de los últimos hallazgos.

Hasta la fecha no se ha recuperado en el registro arqueológico ocupaciones, entre el 16.000 y el 12.500 B.P.. En el caso de la Cueva de Nerja los niveles Magdaleniense Superior (Sala del Vestíbulo NM-7), se encuentran superpuestos a los niveles Solutrenses (Sala Vestíbulo NM-8), por un contacto erosivo (Aura, J.E y. Villaverde, V. 1995). Desconocemos por el momento qué es lo que ocurre con las primeras fases de del Magdaleniense en la región. No ocurre así con la transición Magdaleniense 
Superior Final-Epipaleolítico, que queda atestiguada en los niveles de transición Pleistoceno Superior Final-Holoceno en la Cueva de Nerja.

\section{CONCLUSIONES}

Para los momentos iniciales del Paleolítico Superior en el área de estudio, según se desprende de las secuencias estratigráficas, que son dudosas o están ausentes, podemos concluir con los restos que poseemos, que nos encontramos ante los neandertales más modernos de Europa.

Por otra parte, precisamente por la ausencia de investigaciones sitemáticas, se deconoce la evolución seguida por el Paleolítico Superior en la zona sur de la Península lbérica, donde parece evidente que el poblamiento por parte de los hombres anatómicamente modernos se produjo en los momentos iniciales del Solutrense.

El Solutrense en la Península lbérica se presenta dotado de un gran polimorfismo industrial que queda especificamente patente en las notables diferencias existentes entre la zona cantábrica y el area extracantábrica.

Estas dos zonas quedarían delimitadas por un teórico eje que discurriría desde la desembocadura del Tajo hasta el Sureste de Francia pasando por Madrid. Los principales motivos para señalar las diferencias existentes entre las dos áreas son fundamentalmente de carácter industrial y tipológico, ya que en otros aspectos como el artístico, ofrecen numerosas analogías. Los puntos divergentes se manifiestan en mayor medida en el momento terminal del Solutrense, con la existencia o ausencia de retoque plano sobre las puntas de muesca, así como la presencia o no de puntas de aletas y pedúnculo que ya empiezan a aparecer en el período cultural correspondiente al Solutrense Superior, aunque en Parpalló y Les Mallaetes se encuentran ya en el Solutrense Medio.

En el área mediterránea este horizonte cultural habría que situarlo cronológicamente entre el $20.490 \pm 900 / 800$ B.P. (B.M. 859) (Davidson, I. 1974) del Parpalló (7,25-6,25 metros) calificado como Solutrense Inferior y el $16.500 \pm 280$ B.P. (Gif. 7276) del nivel II de La Cueva de Ambrosio, atribuído a un Solutrense Superior Evolucionado (Ripoll López, S. 1988). Además existen otras dataciones como la de $21.710 \pm 650$ B.P. (KN-l/920) del nivel VI de Les Mallaetes asignado también al Solutrense Inferior (Fortea J. y Jordá, F. 1976), mientras que la de $13.200 \pm 600$ B.P. (M-1019) de la cueva del Reclau Viver (Soler, N. 1986), posiblemente esté contaminada.

Desde el punto de vista cronoestratigráfico habría que situar el Solutrense en un momento final del Würm III e inicios del Würm IV. Los datos 
palinológicos con los que contamos por el momento se limitan a los porporcionados por los yacimientos de La Cueva de Ambrosio y Les Mallaetes. En el caso del primero el Solutrense Medio se correspondería con el interestadio de Laugerie con un clima templado y húmedo. Aquí aumenta el porcentaje arbóreo, alcanzando niveles del $75 \%$, con especies termófilas y húmedas como son el avellano y el tilo (López, P. 1988). Por el contrario, los datos paleoambientales de Les Mallaetes indican unas condiciones cimáticas rigurosas que contrastan con las detectadas en el yacimiento velezano. El Solutrense Superior y el Solutrense Superior Evolucionado de La Cueva de Ambrosio se encuadrarian en el interestadio de Lascaux, igualmente templado pero ligeramente más seco, apareciendo las Compuestas, Rubiaceas y la Ephedra, mientras que en Les Mallaetes estos dos momentos culturales -dentro de una aparente mejoría climática- son atribuidos al interestadio Laugerie-Lascaux sensu lato.

La fauna en casi todos los yacimientos mediterráneos esta dominada principalmente por los lagomorfos (Oryctolagus cuniculus), asociados a restos de cápridos, cérvidos y équidos, así como de otras especies de mamíferos, variando la proporción de esta composición según el entorno en que se encuentran las estaciones.

Tradicionalmente se ha considerado el Solutrense como uno de los períodos mejor conocido de la secuencia cultural del Paleolítico en el Mediterráneo español. Sin embargo, si bien es cierto que son numerosos los yacimientos en los que se ha citado la presencia de alguna pieza integrante del grupo solutrense, son muy pocos los que cuentan con una serie industrial suficientemente representativa como para precisar el momento concreto de su ocupación. Tal es el caso de la cueva de El Parpalló en Valencia y La Cueva de Ambrosio en Almería. Escasos son también los yacimientos que cuentan con un estudio completo y actualizado que incluya todo el espectro de análisis que permitan fijar su posición crono-estratigráfica. En este sentido hay que citar de nuevo el reciente trabajo de La Cueva de Ambrosio, y por supuesto también a la cueva de Les Mallaetes, aunque desgraciadamente este último, y como veremos más adelante, posee un escaso repertorio industrial (32 piezas retocadas en los niveles solutrenses).

Con los datos que disponemos y que acabamos de analizar, es evidente que si queremos presentar una secuencia coherente para el solutrense extracantábrico, se debe hacer de una forma provisional y a la espera de que sea completada medianie nuevos trabajos, sobre todo a partir del estudio y análisis de nuevos yacimientos. Pero por el momento, para establecer dicha secuencia, hay que recurrir de nuevo a los tres yacimientos mencionados anteriormente. Se trata de El Parpalló, del que se 
conoce bien la riqueza de sus colecciones, a pesar de la antigüedad de las excavaciones (Pericot, L. 1942), al contrario de lo que sucede en Les Mallaetes, que es el otro yacimiento solutrense de Valencia, con una secuencia cultural similar a la del Parpalló. Este yacimiento estudiado desde el punto de vista cronoestratigráfico, posee sin embargo un escaso repertorio industrial (Fortea, J. y Jordá, F. 1976).

El otro yacimiento es La Cueva de Ambrosio en Almería, conocido así mismo desde principios de siglo por la riqueza de sus industrias solutrenses, pero, que sin embargo, tiene la ventaja de haber sido excavado recientemente (Ripoll López, S. 1996).

En el Sur de la Península lbérica las industrias del Solutrense Inferior, por otra parte muy escasas, están caracterizadas por el alto porcentaje de puntas de cara plana y la presencia de algunas hojas de laurel. Mientras que en el Solutrense Medio son las hojas de laurel y las puntas de cara plana los tipos más frecuentes entre los útiles solutrenses.

Sin embargo, hay que señalar la existencia de algunas diferencias entre los yacimientos valencianos, donde ya aparecen algunas puntas de aletas y pedúnculo, y La Cueva de Ambrosio donde este tipo es inexistente. A continuación, en el Solutrense Superior, las hojas de laurel siguen siendo muy numerosas, pero apreciamos la aparición de las puntas de muesca con porcentajes relativamente importantes. Siguen estando bien representadas las puntas de cara plana y por el contrario las puntas de aletas y pedúnculo muestran valores poco significativos.

Finalmente, el rasgo más característico del Solutrense Superior Evolucionado es, sin duda, el gran porcentaje de puntas de muesca que muestran un claro predominio frente a los otros tipos del grupo solutrense. Al mismo tiempo las hojitas de dorso alcanzan valores muy altos. Hay, por tanto, un claro dominio del retoque abrupto frente al retoque plano, que presenta índices muy bajos. Pero, a pesar de estos rasgos generales, existe una cierta variabilidad según los yacimientos. Por este motivo en La Cueva de Ambrosio las piezas con retoque plano - a pesar de ser menos abundantes que las puntas de muesca- están presentes en mayor número que en los otros yacimientos de Valencia, donde estos tipos (hojas de laurel y puntas de aletas y pedúnculo) son inexistentes o aparecen escasamente representados en esta fase Solutrense.

Todo esto nos muestra que cada estación puede presentar una dinámica industrial diferente, y solamente una visión global, basada en estudios individualizados para cada yacimiento, puede ayudarnos a establecer un panorama general sobre el comportamiento cultural del Solutrense e en Sur de la Península Ibérica. 
Este complejo industrial, Solutrense Superior Evolucionado, con un aspecto general tan poco solutrense, es contemporáneo del Magdaleniense Inferior y Medio en Francia, si tenemos en cuenta las dataciones radiocarbónicas. La posición cronológica de este período en la España mediterránea junto con algunos rasgos de la industria lítica (ámplio dominio de los útiles sobre hojita), y la gran similitud que presenta la industria ósea hallada en el yacimiento de Almería con la del Parpalló (Pericot, L. 1942), Beneito (Iturbe, G. Cortell, E. y Lorenzo, I. 1982), nos permite sugerir la posible sustitución -en esta región - del Magdaleniense Inferior por el Solutrense Superior Evolucionado. Por otra parte, la similitud de algunos elementos artísticos entre los dos períodos, pueden ayudarnos a sostener esta hipótesis.

Por otra parte el resto de la secuencia magdaleniense está escasamente representada según hemos visto en las páginas anteriores. Esta escasez de yacimientos encuadrables en el Pleistoceno Superior Final, no creemos que se deba asociar a su ausencia, sino más bien a una falta de interés específica por este período, lo que conlleva la falta de prospecciones y estudios sistemáticos.

Es de esperar que las administraciones con competencias en materia de cultura, se replanteen su postura respecto a la investigación, ya que la actual política científica a todas luces restrictiva, refleja el escaso interés por la misma.

\section{BIBLIOGRAFIA}

Arteaga, O., Ramos, J., Roos, A. Ma y Nocete, F. (1993): «Balance a medio plazo del «Proyecto Porcuna». Campaña 1991». En «Anuario Arqueológico de Andalucía 1991. II Actividades sistemáticas: «. Junta de Andalucía. (Sevilla), págs. 295-301

Asquerino, MåD. (1992a): El Pirulejo. Cuadernos de Intervención en el Patrimonio Histórico (Priego de Córdoba), vol. 8, 30 págs.

Asquerino, Mã D. (1992b): «El Pirulejo. Avance de la Campaña de 1991». ANTIQVITAS (Priego de Córdoba), vol. 3 , págs. 3-7.

Asquerino, MãD. (1993): «El Pirulejo (Priego de Córdoba). Informe sobre la campaña de 1991». En «Investigaciones arqueológicas en Andalucía 1991. II. Actividades sistemáticas". Junta de Andalucía. (Sevilla), págs. 116-119

Aura J. E. (1986): La ocupación Magdaleniense de la Cueva de Nerja (Sala de la Mina). En «La Prehistoria de la Cueva de Nerja (Málaga) (J. F. Jordá Pardo edit. y coord.)". Trabajos sobre la Cueva de Nerja, Patronato de la Cueva de Nerja. (Málaga), vol. 1, págs. 207-267.

Aura J. E. y VILlaverde, V. (1995): El Paleolítico Superior final y Epipaleolítico en la España Mediterránea (18.000-9.000 B.P.) En. El Final del Paleolítico Cantábrico. Transformaciones ambientales y culturales durante el Tardiglaciar y el Holoceno en la región cantábrica. (A Moure y C. González edits.), Universidad de Cantabria, Santander, págs. 313-340

Baldomero, A., Ferrer, J. y Marques, I. (1991): «Excavaciones de urgencia en el Bajondillo (Torremolinos, Málaga)». En «Investigaciones arqueologicas en Andalucía. 1989. III. Actividades de Urgencia:». Junta de Andalucía. (Sevilla), págs. 357-359.

Baldomero, A., Marques, I. y FerRer, J. (1989-90): «Intervención de urgencia en el Bajondillo (Torremolinos, Málaga)". Mainake (Málaga),.vol. XI-XII, págs. 11-20. 
Barroso, C., Hublin, J. J., Medina, F., Rodríguez, J. y Martín, E. (1991): «Proyecto Zafarraya y el reemplazamiento de los neandertales por el hombre anatómicamente moderno en Europa Meridional». En «/V Jornadas de Arqueología Andaluza: 15-19 de Enero de 1991, Jaen». Junta de Andalucía. (Sevilla), págs. 23-33.

CACHo Quesada, C. (1980): «La secuencia cultural del Paleolítico Superior en el Sureste español». Trabajos de Prehistoria (Madrid), vol. 37, págs. 65-108...

Cacho Quesada, C. (1997): Le Paléolithique Supérieur en Espagne Meditérranéenne: Valence, Murcie et Andalousie". En UISPP, Congrés de Forli, 1996, Commission Paléolithique Supérieur , Bilan 1991-1996, ERAUL 76, págs. 353-367.

Cacho, C.; Fumanal, Mạp.; López, P.; López, J.A.; Pérez-Ripoll, M.; Martinez, R.; Uzquiano, P.; Arnaiz, A.; Sánchez, A.; Sevilla, P.; Morales, A.; Roselló, E.; Garralda, Mão. y Garcia, M. (1995): «El Tossal de la Roca (Val d'Alcalá, Alicante). Reconstrucción paleoambiental y cultural de la transición del Tardiglaciar al Holoceno Inicial.». Recerques del Museo de Alcoy (Alcoy), núm. IV, págs. 11-101.

CoRTÉs, M. y Simón, M. D. (1997): «Cueva de Nerja (Torremolinos, Málaga). Aportaciones al Paleolítico en Andalucía» Coloquio Internacional de Bañolas 1995."El món mediterrani després del Pleniglacial (18.000-12.000 B.P.)» (J.M² Fullola y N. Soler eds.). Centre d'Investigacions Arqueologiques, Serie Monogràfica (Girona), núm. 17, págs. 275-289,

Cortés, M., MuÑoz, V. E., SANChIDRIÁN, J. L. y SIMÓN, M. D. (1996): «El Paleolítico en Andalucía: La dinámica de los grupos predadores en la Prehistoria andaluza. Ensayo de síntesis. Repertorio bibliográfico de 225 años de investigación (1770-1995)", pags. 213. Córdoba.

DAvidson I. (1974): Radiocarbon dates for the Spanish Solutrean. "Antiquity» (Londres), vol. 48, 1974, p. $63-65$

ForteA, J. (1970): «La cueva de La Palica. Serrón (Antas). Avance al estudio del Epipaleolítico del S.E. peninsular». Trabajos de Prehistoria (Madrid), vol. 27, págs. 61-96.

Fortea PÉrez, J. (1984): «El Paleolítico Superior y Epipaleolítico en Andalucía. Estado de la cuestión cincuenta años después». En Homenaje a L. Siret (1934-1984), Consejeria de Cultura de la Junta de Andalucía (Sevilla), págs. 68-78.

Fortea , J. y JoRDÁ, F. (1976): «La Cueva de Les Mallaetes y los problemas del Paleolítico Superior del Mediterráneo español». Zephyrus (Salamanca), vol. XXVI-XXVII, págs 127166.

FulLOLA PERICOT, J.Ma (1978): «EI Solutreo-Gravetiense o Parpallense, industria mediterránea». Zephyrus (Salamanca), vol. XXVIII-XXIX, págs. 113-125.

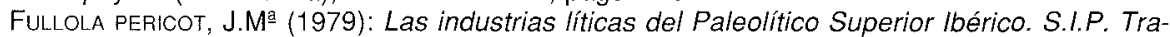
bajos Varios (Valencia), vol. $60: 262$ págs.

FULLOLA PERICOT, J.M (1994): «El solutrense en la región mediterránea y Andalucía». Férvedes (Villalba), t. 1, págs. 105-118.

Giles, F., Gutiérrez, J. M., Mata, E., Santiago, A. y Gracia, J. (1993): «Prospecciones arqueológicas y análisis geocronológicos y sedimentarios en la cuenca del río Guadalete. Secuencia fluvial y paleolítica del río Guadalete (Cádiz). Resultados de las investigaciones hasta 1993». En «Investigaciones arqueológicas en Andalucía. 1985-1992. Proyectos: «Junta de Andalucía. (Huelva), págs. 211-227

Glles, F., Gutiérrez, J. M., Santiago, A. y Mata, E. (1995-96): «Avance al estudio sobre el poblamiento del Paleolítico Superior en la cuenca media y alta del río Guadalete (Cádiz)». Boletín del Museo de Cádiz, vol. VII, págs. 37-61.

Giles, F., GutiérRez, J. M., Santiago, A. y MATA, E.(en prensa): «Avance al estudio sobre el poblamiento del Paleolítico Superior en la cuenca media y alta del río Guadalete (Cádiz)». En «/ Simposio de Prehistoria de la Cueva de Nerja. Abril, 1996. Nerja.

Giles, F., GutiérRez, J. M., Santiago, A. y MATA, E. (1992): «Secuencia paleolítica del valle del Guadelete. Primeros resultados». Revista de Arqueología (Madrid), no 135, págs. 16-26.

Giles, F., Santiago, A., Gutiérrez, J.M., Mata, E. y Agullera, L. (1996): «Nuevas evidencias de Paleolítico Superior en el extremo sur europeo\%. Caetaria (Algecrias), nº 1, págs. 11-18.

GimÉNEZ, S. y LAZA, M. (1962): «Informe de las excavaciones de la Cueva del Higuerón (Málaga)». Noticiario Arqueológico Hispano (Madrid), vol. 6, págs. 60-67.

GonzÁlez TABLAS, F.J. (1986): La ocupación Postmagdaleniense de la Cueva de Nerja (Sala de la Mina). En «La Prehistoria de la Cueva de Nerja (Málaga) (J. F. Jordá Pardo edit. y coord.)». Trabajos sobre la Cueva de Nerja, Patronato de la Cueva de Nerja. (Málaga), vol. 1, págs. 271-282. 
Gutiérrez, J. Ma , Santiago, A., Giles, F., García, F. J. y Mata, E. (1994): «Áreas de transformación de recursos líticos en glacis de la Depresión de Arcos de la Frontera (Cádiz)». En "Geoarqueología. Actas de la II Reunión Nacional de Geoarqueología (J.F. Jordá, de.): Madrid, 1992». ITGE-AEQUA. págs. 305-316

Hublín, J. J., Barroso C., Medina, F., Fontugne, M. y Reyss, J. L. (1995): «The Mousterian site of Zafarraya (Andalucia, Spain): dating and implications on the palaeolithic peopling processes ofwestern europe" Compes Rendus de l'Academie des Sciences de Paris (Paris), $t$. 321 , págs. $931-937$.

Iturbe Polo, G; Cortell Pérez, E. y Lorenzo Magalón, I. (1982): Cova Beneito: Avance preliminar. "Saguntum» (Nalencia), págs. 9-44, 23 figuras.

ItURbe, G. y CoRTEli, E. (1987): «Las dataciones de Cova Beneito y su interés para el Paleolítico Mediterráneo". Trabajos de Prehistoria (Madrid), vol. 44, págs. 267-270.

JoRDÁ CERDÁ, F. (1955): El solutrense en España y sus problemas,. Diputación Provincial de Asturias. (Oviedo), 200 págs.

JoRdá CERdÁ, F. (1986): «La ocupación más antigua de la Cueva de Nerja». En «La Prehistoria de la Cueva de Nerja (Málaga) (J. F. Jordá Pardo edit. y coord.) ss. Trabajos sobre la Cueva de Nerja, Patronato de la Cueva de Nerja. (Málaga), vol. 1, pp. 197-204.

Jordá Cerdá, F.; Jordá Pardo, J.F.; Gonzalez-Tablas, F.J.; Aura, E. y Sanchidrián, J.L. (1983): "La Cueva de Nerja». Revista de Arqueología (Madrid), núm. 29, págs. 56-65.

Jordá Cerdá, F.; Jordá Pardo, J.F..; González-Tablas, F.J.; Aura, E. y Sanchidrián, J.L. (1991): "Paleoambiente y secuencia cultural de la Cueva de Nerja (Málaga): La Sala del Vestíbulo". En "Resúmenes de las comunicaciones de la VIII Reunión Nacional sobre Cuaternario: Medios Sedimentarios, Cambios Ambientales y Hábitat Humano". Valencia.

López, P y CACHO QuesAdA, C.(1979): «La Cueva del Higuerón (Málaga): estudio de sus materiales. Trabajos de Prehistoria, 36, pp 11-82, Madrid.

MARQUĖs l. y FERRER, J. E. (1991): «Hallazgo de industria Solutreogravetiense en el Bajondillo (Torremolinos, Málaga)» Baetica (Málaga), vol. 13, págs. 137-146.

MuNoz, F.J. (1997): "La punta de muesca de tipo mediterráneo: análisis tecnológico y funcional». Trabajos de Prehistoria (Madrid), vol. 54 (1), págs. 99-119.

OlaRIA, C. (1997): Las dataciones de C14 del Tardiglaciar al Holoceno en la vertiente mediterránea en la Península lbérica: una hipótesis de periodización. Revista d'Arqueologia de Ponent (Castellón), vol. 7, págs. 7-23.

PERICOT, L. (1942): La cueva del Parpalló (Gandia). Excavaciones del Servicio de Investigación Prehistórica de la Diputación de Valencia. Instituto Diego Velázquez (Madrid), 351 págs.

PERICOT, L. (1949): “El Paleolítico Superior del Sudeste». En «V Congreso Arqueológico del Sudeste Español y / Congreso Nacional de Arqueología:, Almería, 1949». (Cartagena), págs. 57-62

MARqués, I. y Ruiz, C. (1976): «El Solutrense de la cueva del Tajo del Jorox (Alozaina, Málaga)". Cuadernos de Prehistoria de la Universidad de Granada, vol. 1, págs. 47-57.

Marti, B. y Gil, J. (1978): «Perlas y aletas de glóbulos del Cau del Raboser». Archivo de Prehistoria Levantina (Valencia), vol. XV, págs. 47-68.

PLÁ, E. (1978): "Prehistoria y Protohistoria». En «Iniciación a la historia de Oliva». Ayuntamiento de Oliva. Oliva.

Ramos Muñoz, J. (1994): «El Paleolítico Superior en la Bahía de Málaga. Reflexiones para un necesario debate» SPAL (Sevilla), t. 3, págs. 73-85.

Ramos, J., Borja, F. Sáez, A., Castañeda, V., Ceplllo, J. y Pérez, M. (1992): «La ocupación prehistórica de la campiña litoral y la banda atlántica de Cádiz». En «Investigaciones Arqueológicas en Andalucia (1985-1992). Proyectos: «. Junta de Andalucía. (Sevilla), págs. 353-366.

Ramos, J. R., CAstañeda, V. y Garcia. F. J. (1995): «El asentamiento al aire libre de La Fontanilla (Conil de la Frontera, Cádiz). Nuevas aportaciones para el estudio de las comunidades de cazadores-recolectores especializados en la banda atlántica de Cádiz». Zephyrus, XLVIII: 269-288. Salamanca.

Ramos, J., Castañeda, V., Pérez, M., Lazarich, M., González, M., Montañés, M., Arroquia, M., Blanes, C., Martínez, C., Domínguez, S., Garcia, J., Morata, Pérez, L., D., Gómez, M., Herrero, n., Reina, A., Cantalejo, P., Brito, M., Guzmán, J., Calderón, J., lozano, J. y SoRIANO, M. (1995): El Paleolítico Superior Final del río Palmones (Algeciras, Cádiz). Un ejemplo de la tecnología de las comunidades especializadas de cazadores-recolectores. Instituto de Estudios Campogibraltareños (Algeciras), 251 págs. 
Ramos, J. R., Castañeda, V., Pérez, M. Lazarich, M. y Montañés, M. (1995-96): «Aportaciones al estudio del modo de producción de los cazadores-recolectores especializados y al inicio de la economía de producción en la banda atlántica de Cádiz (sur de España)". Boletín del Museo de Cádiz, vol. Vll, págs. 7-35.

Ripol Perelló, E. (1960-61): «Excavaciones en Cueva de Ambrosio (Vélez Blanco, Almería). Campañas 1958 y 1960». Ampurias (Barcelona), vol. XXII-XXIII, págs. 31-45.

Ripoll Perelló, E. (1962): «Excavaciones en Cueva de Ambrosio (Vélez Blanco, Almería)». En «VII Congreso Nacional de Arqueología: Barcelona. 1961 (Zaragoza), págs. 117-121.

Ripoll PeRElló, E. (1970): «Acerca del problema de los origenes del arte Levantino. En Valcamonica Symposium, Centro Camuno di Studi Preistorici (Italia), págs. 57-67.

Ripoll López, S. (1984): El Solutrense de La Cueva de Ambrosio (Vélez-Blanco, Almería): Campaña de 1963. Excavaciones Arqueológicas en España (Madrid), nº 148, 205 págs.

RIPOLL LóPEZ, S. (1988): El Solutrense de la Cueva de Ambrosio (Almería, Spain) y su posición cronoestratigráfica en el Mediterráneo Occidental. B.A.R. International Series (Oxford). vol. 462, 596 págs. (2 vols.).

Ripoll López, S., MAS, M. y Perdigones, L. (1993): «Actuaciones de urgencia en las Cuevas de Levante y Cubeta de la Paja (Sierra Momia, Benalup, Cádiz)". En «Investigaciones arqueológicas en Andalucía. 1991. Il. Actividades sistemáticas:". Junta de Andalucía. (Sevilla): $105-110$.

Ripoll lópez, S., Muñoz, F.j. Paniagua, J.P. Calleja, F. y Amaya, C. (1997): «la Cueva de Ambrosio (Almería): nuevas aportaciones. El arte rupestre paleolítico». Coloquio Internacional de Bañolas 1995. »El món mediterrani després del Pleniglacial (18.000-12.000 B.P.)»

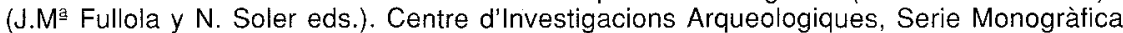
(Girona), núm.17, págs. 385-398.

Rifoll lópez, S,. PÉrez, S. López, J.R. Martos, J.A. y Muñiz, M. (1997): «Las estructuras de combustión de la Cueva de Ambrosio. Estudio preliminar». Coloquio Internacional de Bañolas 1995. El món mediterrani després del Pleniglacial (18.000-12.000 B.P.) (J.M Fullola y N. Soler eds.). Centre d'Investigacions Arqueologiques, Serie Monogràfica (Girona), núm.17, págs. 399-409.

SANCHIDRIÁN, J.L. (1992): «Los primeros datos sobre las industrias del Paleolítico Superior en Andalucía Occidental». Saguntum-PLAV, 25: 11-25. Valencia.

SANCHIDRIÁN, J.L. (1994): «Arte paleolítico en la zona Medridional de la Península lbérica». Complutum (Madrid), vol. 5, págs. 163-195.

SANCHIDRIÁN, J.L.; JoRdÁ, J.; GABRIELA, M. y JORDÁ, F. (1987): "Excavaciones en la Cueva de Nerja». Revista de Arqueología (Madrid), núm. 79, págs. 62-64..

Soler MasferRer, N. (1986): Les industries del Paleolitic Superior en el Nord de Catalunya. Tésis Doctoral leida en la Universidad Central de Barcelona. Inédita.

Soler, B., Badal, E., Villaverde, V. y AuRA, J.E. (1990): «Nota sobre un hogar solutreogravetiense del abric de la Ratlla del Bubo (Crevillente, Alicante)». Archivo de Prehistoria Levantina (Valencia), vol. XX, págs. 79-92.

Such, M. (1919) «Avance al estudio de la caverna de Hoyo de la Mina en Málaga. Boletín de la Sociedad Malagueña de Ciencias. (Málaga).

TORO, I. y Almohalla, M. (1979): «Industrias del Paleolítico Superior en la provincia de Granada». Cuadernos de Prehistoria de la Universidad de Granada, vol. 4, págs. 1-20.

TORO, I. y Almohalla, M. (1985a): «Descubrimiento de industrias del Paleolítico Superior en la provincia de Granada. El yacimiento solutrense de la Cueva de los Ojos (Cozvíjar, Granada)». En "XVII Congreso Nacional de Arqueología:, Logroño, 1983». (Zaragoza), págs. 97104

Toro, I.y Almohalla, M. (1985b): «Le gisement de la Cueva de los Ojos (Cozvíjar, Granada)». Bulletin de la Société Préhistorique Française (París), vol. 82, págs 116-119.

Toro, I., Almohalla, M. y Argamasilla, M. (1980): «Nuevas aportaciones al conocimiento de las industrias del Paleolítico Superior en la provincia de Granada". Cuadernos de Prehistoria de la Universidad de Granada (Granada), vol. 5, págs.1-14.

Toro, L., Almohalla, M. y Martín, E. (1984): El Paleolitico en Granada. Hombres, culturas, faunas, floras y climas en la provincia de Granada desde 1.500 .000 a 10.000 años. Trabajos del Museo Arqueológico de Granada (Granada), vol. 2, 67 págs.

Vega Toscano, L. G. (1988): «El Paleolítico Medio del Sureste español y Andalucía Oriental» Serie Tesis Doctorales, Universidad Complutense (Madrid), 4 tomos, pags. 2364. 
VILLAVERdE, V. (1979): «El solutrense en el País Valenciano: estado actual de su conocimiento». Saguntum-PLAV (Valencia), vol. 14, págs. 9-31.

VILLAVERDE, V. (1992): «El Paleolítico en el País Valenciano». En Aragón/Litoral Mediterráneo: Intercambios culturales durante la Prehistoria. En Homenaje a Juan Maluquer de Motes (P. Utrilla coord.) Instituto Fernando el Católico. (Zaragoza), págs. 55-87. 